\title{
Application of Multiple Intelligence Theory in the Design of College Professional Training Target Matrix
}

\author{
Zhen Li \\ JinCheng College of Sichuan University \\ Chengdu, China
}

\begin{abstract}
The development of professional teaching plans and training target matrix is an important part of the design professional curriculum system. However, the existing evaluation methods of the curriculum system through knowledge, ability and quality indicators are not intuitive enough to be applied to the long board principle. Based on the application of multiple intelligence theory, this work transformed the past threedimension indicators into five dimension indicators to address the aforementioned two problems and proposed a transformation paradigm as a way forward.
\end{abstract}

Keywords-Multiple intelligence; Long board principle; Training target matrix

\section{INTRODUCTION}

In higher education, each major carefully designs, develops, and standardizes the curriculum requirements at each stage through a teaching plan and a training target matrix. In the process of revising the professional teaching plan, the revision of the professional training target matrix will be involved. However, the training target matrix, which is currently used, can't directly reflect the requirements of students.

\section{RESEARCH FOUNDATION}

\section{A Multiple intelligence theory}

At the end of the 20th century, Howard Gardner, a professor at Harvard University in the United States, put forward the multiple intelligence theory in his book "The Structure of Intelligence: Multiple Intelligence Theory". Including language-language intelligence, logic-building intelligence, visual-spatial intelligence, music-rhythm intelligence, body-motion intelligence, interpersonal communication intelligence, self-introspection intelligence, natural observation intelligence, presence intelligence. In the 1990s, the multiple intelligence theory was introduced into China and was widely used in many fields. This theory is in line with the current background of China's needs for talent training, and has important guidance and reference significance for the cultivation of talents in China [1].
$B$ The structure of knowledge, ability and quality in higher education design

In the design and formulation of higher education curriculum teaching system, three evaluation indexes are usually used to evaluate three dimensions, namely knowledge structure, ability structure and quality structure [2]. In 1987, Hong Cikun defined systematic knowledge education as knowledge structure and scientific practice as ability structure [3]. In addition, Qu Lixue specifically defined the structure of knowledge and ability in 1989. Knowledge structure refers to basic knowledge, structure and method, and knowledge understanding. Ability structure refers to cognitive ability, thinking ability and application ability [4].

\section{The intelligence division of higher education}

In 2018, He Canxiu said that the multiple intelligence theory is the basis for the reform of higher education curriculum in China. Teaching through multiple intelligence is an opportunity for students to better use and develop their multiple intelligence [5]

Combining the system of higher education, students and curriculum characteristics, the multiple intelligence theory puts forward that multiple intelligence can be divided into general intelligence, social intelligence, emotional intelligence, interpersonal intelligence and social intelligence [6]. Specific definitions of five dimensions are shown as Table I.

TABLE I. FIVE DIMENSIONAL DEFINITIONS

\begin{tabular}{|c|c|}
\hline Dimension & Definition \\
\hline General intelligence & Intelligence is above 90 \\
\hline Social intelligence & Understanding and accepting yourself \\
\hline $\begin{array}{c}\text { Emotional } \\
\text { intelligence }\end{array}$ & $\begin{array}{c}\text { Regulating and controlling emotions can correctly } \\
\text { recognize emotions }\end{array}$ \\
\hline $\begin{array}{c}\text { Interpersonal } \\
\text { intelligence }\end{array}$ & $\begin{array}{c}\text { The ability to build a harmonious relationship with } \\
\text { others }\end{array}$ \\
\hline $\begin{array}{c}\text { Social intelligence } \\
\text { dynamic interaction among people, things and things } \\
\text { in the environment }\end{array}$ \\
\hline
\end{tabular}




\section{DESIGN OF TRAINING TARGET MATRIX BASED ON MULTIPLE INTELLIGENCE THEORY}

\section{A Training target matrix}

The curriculum contained in the training target matrix is exactly the same as that in the teaching plan, and each course is divided into knowledge structure, ability structure and quality structure through the knowledge element structure. The knowledge structure, ability structure and quality structure all contain a number of specific project indicators (see Table II).

TABLE II. KNOWLEDGE, ABILITY AND QUALITY INDICATORS

\begin{tabular}{|c|c|}
\hline Training target & Indicators \\
\hline \multirow{6}{*}{ Knowledge } & Humanities knowledge \\
\hline & Social science knowledge \\
\hline & $\begin{array}{l}\text { Natural science knowledge and basic and frontier } \\
\text { knowledge of engineering technology }\end{array}$ \\
\hline & Basic knowledge of mathematics \\
\hline & Basic knowledge of economy and management \\
\hline & Knowledge of common computer tools \\
\hline \multirow{8}{*}{ Ability } & Critical consciousness and independent thinking ability \\
\hline & Information acquisition and comprehensive ability \\
\hline & Accurate expressive ability of language and writing \\
\hline & $\begin{array}{c}\text { Communication coordination, teamwork and } \\
\text { organizational management ability }\end{array}$ \\
\hline & $\begin{array}{l}\text { Ability to discover, analyze and solve problems with } \\
\text { applied expertise }\end{array}$ \\
\hline & Foreign language application ability \\
\hline & $\begin{array}{c}\text { Preliminary aesthetic ability of literary and artistic } \\
\text { works }\end{array}$ \\
\hline & Lifelong autonomous learning ability \\
\hline \multirow{8}{*}{ Quality } & Physical and mental health \\
\hline & Spirit, ideals and beliefs \\
\hline & Morality, integrity, tolerance, tolerance \\
\hline & Will, perseverance and style \\
\hline & $\begin{array}{c}\text { Professional ethics, responsibility, dedication, and } \\
\text { initiative }\end{array}$ \\
\hline & Criticism, thinking and innovation \\
\hline & Psychological quality, social adaptation \\
\hline & Values, hardship \\
\hline
\end{tabular}

From the table, we can see that there are 22 indicators in the knowledge dimension, ability dimension and quality dimension.

However, according to the characteristics of the curriculum, not all the above three dimensions and 22 specific indicators will be required. For example, advanced mathematics courses, which do not contain the following indicators, can be seen from the table (see Table III). Quality evaluation does not include spirit, ideals and beliefs; morality, integrity, tolerance and tolerance; will, perseverance and style; professional ethics, responsibility, dedication and initiative; physical and mental health. Knowledge evaluation does not include knowledge of common tools in computers.

TABLE III. INDICATORS ARE NOT INCLUDED

\begin{tabular}{|c|c|c|}
\hline $\begin{array}{c}\text { Evaluative } \\
\text { dimension }\end{array}$ & Indicators & Remarks \\
\hline \multirow{4}{*}{ Quality } & Spirit, ideals and beliefs & Not required \\
\cline { 2 - 3 } & Will, perseverance and style & Not required \\
\cline { 2 - 3 } & $\begin{array}{c}\text { Professional ethics, responsibility, } \\
\text { dedication, and initiative }\end{array}$ & Not required \\
\cline { 2 - 3 } & Physical and mental health & Not required \\
\hline Knowledge & $\begin{array}{c}\text { Computer common tool } \\
\text { knowledge }\end{array}$ & Not required \\
\hline
\end{tabular}

\section{$B$ Definition of evaluation indicators}

The three-dimensional structure of knowledge, ability and quality is divided into different evaluation indicators, in which the knowledge structure is divided into six specific evaluation indicators. The ability structure is divided into eight specific evaluation indicators, and the quality structure is divided into eight evaluation indicators.

We define these indicators in detail to determine their essential meaning. By understanding the essential meaning and explaining the five dimensions of intelligence in the multiple intelligence theory, 22 indicators of intelligence can be regrouped.

\section{Transformation of evaluation indicators}

According to the multiple intelligence theory, the indicators are re-divided into five kinds of intelligence: general intelligence, social human intelligence, emotional intelligence, interpersonal intelligence and social intelligence. There are 4 items in the general intelligence dimension, 10 items in the social intelligence dimension, 1 item in the emotional intelligence dimension, 1 item in the interpersonal intelligence dimension and 6 items in the social intelligence dimension.

Through this way of division, we can clearly find that the number of indicators covered by the five kinds of intelligence is different, and the proportion is different. The proportion of social intelligence, social human intelligence, general intelligence, interpersonal intelligence and emotional intelligence were $27.2 \%, 45.4 \%, 18.1 \%, 4.5 \%$ and $4.5 \%$, respectively.

Taking higher mathematics as an example, it can be transformed into five dimensions (see Table IV)

TABLE IV. MULTIPLE INTELLIGENCE INDICATORS

\begin{tabular}{|c|c|c|}
\hline Multiple intelligence & Indicators & Remarks \\
\hline \multirow{6}{*}{ Social intelligence } & Humanities knowledge & Required \\
\hline & Social science knowledge & Required \\
\hline & Natural science knowledge and basic and frontier knowledge of engineering technology & Required \\
\hline & Information acquisition and comprehensive ability & Required \\
\hline & Accurate expressive ability of language and writing & Required \\
\hline & Ability to discover, analyze and solve problems with applied expertise & Required \\
\hline \multirow{4}{*}{ Social human intelligence } & Critical consciousness and independent thinking ability & Required \\
\hline & Preliminary aesthetic ability of literary and artistic works & Required \\
\hline & Lifelong autonomous learning ability & Required \\
\hline & Physical and mental health & Not required \\
\hline
\end{tabular}




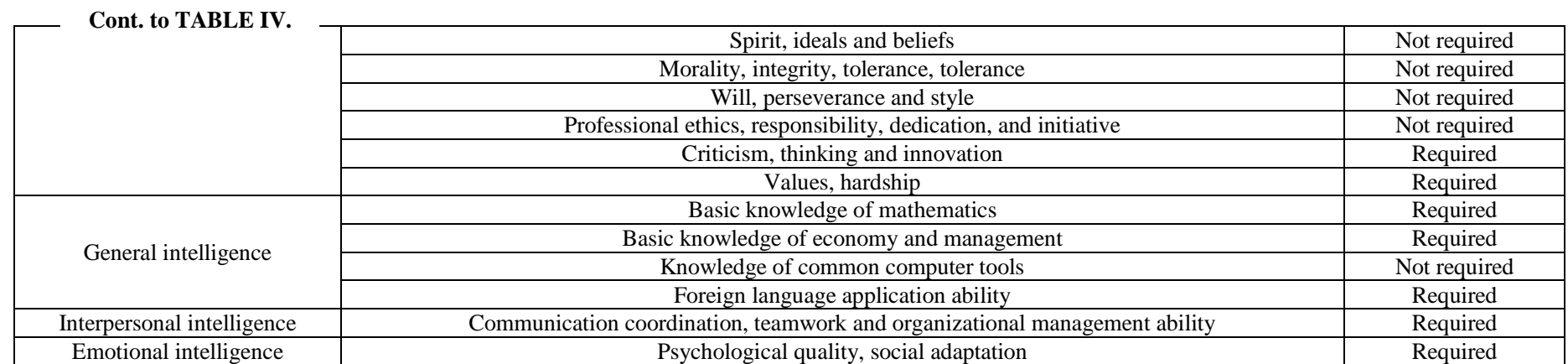

\section{$D$ Interpretation of multiple intelligence indicators}

It can be seen from the table that the teaching goal of higher mathematics requires students to master six abilities to understand the environment, five abilities to understand themselves, three basic intellectual requirements, one ability to communicate with others and one ability to control their emotions. Through the different proportion of the five dimensions for higher mathematics and the different indicators of each dimension, we can see that in the dimension of social intelligence, the purpose of curriculum learning is to hope that students can understand the social environment more clearly. In the dimension of social intelligence, the aim of curriculum learning is to hope that students have the spirit of critical thinking and perseverance. In the general intelligence dimension, the curriculum requires higher basic skills. However, the requirements of curriculum in interpersonal communication and emotional control are low.

\section{RESEARCH RESULTS}

\section{A It is more conducive to the evaluation of students}

We transform the commonly used knowledge, ability and quality structure in teaching design into multiple intelligence indicators through the multiple intelligence theory. We evaluate the design of curriculum system through five dimensions, and present the characteristics of professional courses in a more intuitive and easy-to-understand way, which is helpful for the teacher to quickly grasp the characteristics of the students and is more conducive to the students to quickly recognize their own strengths.

\section{B Providing indicator and method basis for practicing long board principle}

Long board principle: For a learner in the higher education stage, his growth and success often depend on his "long board" (prominent advantages) when the basic aspects (such as good moral character, healthy body, necessary knowledge and cultural reserves) are qualified [7]. But how to discover the outstanding advantages of students and what indicators to evaluate and explore, using the traditional knowledge element model can't be intuitively reflected. The transformation of knowledge, ability and quality model through the multiple intelligence theory has solved the shortcomings of unobtrusive and unintuitive evaluation indicators, and provided theoretical and practical basis for the implementation of long board theory.

Therefore, through the definition of these indicators, we can find that each intelligence dimension represents a long board. If students have higher scores in several intelligence dimensions, they have stronger abilities and talents in these fields. On the contrary, if students show a lower score in a certain intelligence dimension, it means that there are obvious shortcomings in these areas.

\section{Promotion of curriculum design paradigm}

From the perspective of school, it is more intuitive and easy to understand that the paradigm of knowledge, ability and quality structure can be transformed into the paradigm of intelligence structure. We can adjust the corresponding indicators according to the different nature of schools, colleges, majors and courses and the requirements of each intellectual dimension. We can also adjust the corresponding weight according to the different characteristics and requirements of each course, so as to fully reflect and embody the requirements of curriculum and professional characteristics.

From the perspective of student, this kind of teaching and curriculum design based on intellectual structure has a better guiding role for students to recognize their own characteristics. Students can quickly identify which dimension they have advantages and which dimension they have shortcomings. And according to their own characteristics, they can choose to make up for the shortcomings, give full play to their advantages, or avoid the shortcomings, consolidate the advantages of the strategy for learning.

From the perspective of teacher, the curriculum is reexamined from the perspective of teachers themselves and students themselves by combining the intellectual and intellectual structures of the curriculum. Through the performance of each indicator in the student's intellectual structure, understanding the characteristics of the students themselves, and then transforming into a matrix of knowledge structures can intuitively understand the problem of knowledge, ability or quality.

\section{CONCLUSIONS}

The multiple intelligence theory has an important reference role in the field of education in China, but a large number of applications mainly involve preschool and primary education stages, and relatively few in higher education. The main reason is that its original evaluation indicators are not suitable for the evaluation requirements of higher education. It is noteworthy that some indicators suitable for higher education evaluation have been put forward in this field. Based on this theory, this work combined knowledge, ability, and quality models to transform the evaluation indicators for the education system into evaluation indicators for teachers and students. 
Furthermore, combining with the long board theory proposed by Jincheng College of Sichuan University, it can show the characteristics of specialties and courses more clearly, effectively and accurately. It provides a basis for teachers to design and evaluate courses, and provides a reference for students to evaluate and identify themselves. Based on the multiple intelligence theory, the research in the field of curriculum system design in higher education has also been filled in.

\section{REFERENCES}

[1] Pu Xiaoping: Multiple Intelligence Theory and Talents Cultivation [J], Learning Theory, No. 3, 2011, P. 58.

[2] Jiang Xiaoyan: An Analysis of Teaching Plan for Computer Multimedia Technology Specialty [J], Coal Technology, No. 2, 2012, PP. 274-275.

[3] Hong Cikun: Consideration on the Functional Structure of the Hydraulic Engineering Specialty in the Academy [J], Journal of Jiangxi Water College, 1987, pp. 15-20.

[4] Qu Lixue: Mathematics Teachers' Knowledge and Ability Structure and Course Learning [J], Journal of Qiqihar Normal University, No. 8, 1989, pp. 95-99.

[5] He Canxiu: Application of Multiple Intelligence Theory in Higher Vocational Education [C]. Excellent Papers of 2008 Annual Conference (Higher Vocational Education) in Yunnan Higher Education Society, No. 12, 2008, pp. 302-311.

[6] Zhou Houyu: Fostering Students' Multiple Intelligence in College Teaching [J], Educational Modernization, No. 6, 2016, pp. 74-75.

[7] Li Xiufeng: On the "Long Board Principle" of Talents Cultivation in Colleges and Universities [J], Overseas Students, No. 2, 2015, p. 11. 